\title{
Design on Non - deceleration ETC Toll System based on RFID Technology
}

\author{
Tao Xiaoheng \\ Huanggang Polytechnic College, Hubei, China, 438002
}

Keywords: Road and bridge toll system; RFID technology; non-deceleration ETC

\begin{abstract}
At present, China's road and bridge toll collection system mainly adopts two methods: the first is manual toll collection, and the second is vehicle deceleration ETC toll collection. Those will result in inefficient traffic flow. Based on RFID technology, this paper optimizes the vehicle deceleration ETC charging mode, and designs the vehicle non-deceleration ETC charging system, which improves the efficiency of toll cars on roads and Bridges.
\end{abstract}

\section{Introduction}

\subsection{ETC introduction}

ETC is an electronic toll collection system for roads, Bridges and tunnels. It began to rise in the 1980s and was widely used in developed countries in the 1990s. The most important feature of ETC is no parking fee. Compared with the traditional manual toll system, ETC system has higher capacity. ECT can effectively relieve traffic congestion at toll booths and reduce environmental pollution. ECT can make highway toll management paperless and cashless. This fundamentally put an end to the problems, such as the fare charges loss and fees management chaos. In addition, ECT can also save the cost of toll station construction and management costs. ETC system is the development trend of highway toll collection in the future. In the domestic application is also gradually carried out, but the progress is slow.

\subsection{ETC classification}

ETC can be divided into deceleration ETC toll system and non - deceleration ETC toll system. The main characteristics of the deceleration ETC system are as follows. Vehicles passing through the toll lanes travel at a lower speed, usually between $30 \mathrm{~km} / \mathrm{h}$ and $50 \mathrm{~km} / \mathrm{h}$. The pass rate is $600 / \mathrm{h}$ to $1000 / \mathrm{h}$. Automatic railings are installed at the exit of the lane. In this way, car-free vehicles are prevented from passing. The main characteristics of the non - deceleration ETC system are as follows. First, there are no toll booth facilities. Second, there is no need to slow down when entering the toll point. The vehicle traffic capacity is close to 2000 vehicles /h. Third, it is necessary to establish a set of high-precision evidence collection and processing system for evading fees. The main advantages of this system are small construction investment, high speed, no traffic delays and so on. However, the equipment investment is large, and the technology is difficult to achieve, especially how to prevent and curb evading vehicles is the key technology.

\subsection{The application situation of ETC charge system in China}

At present, road and bridge toll collection system in China mostly adopts manual toll collection, ETC is a less. The main reason is that the management system in China is decentralized, and there is no unified ETC system. Which will lead the user feeling inconvenient, resulting in ETC usage rate is very low. At present, ETC has been used mainly for the deceleration ETC system, mainly to prevent vehicles from evading fees.

\section{The insufficient of ETC charging method}

Vehicle deceleration ETC has made great progress compared with manual charging method. The vehicle needs to slow down when passing. It still reduces efficiency. The following main analysis the insufficiency about the deceleration ETC and non - deceleration ETC. 


\subsection{The shortcomings of deceleration ETC}

ETC technology is the last century $80 \mathrm{~s}$ technology, mainly have the following shortcomings. First, the accuracy is low on the automatic license plate recognition system and vehicle type classification system. The recognition rate is less than $90 \%$, and it is easily affected, such as dirty license plate, weather, etc. At present, many ETC use to read the vehicle license plate and vehicle type directly in the OBU. However, the unit handling OBU vehicle system is not unified, which is easy to Cheating on exams. The OBU may be stolen or replaced. And the aim is to pay less. Second, the following interference is serious. The following interference is when two cars are passing the ETC lane, RSU made a deal with the OBU of the rear car. When the driveway railing is raised, the untraded front car pulls out of the driveway, the closed back car is stopped, and the driveway is alerted. Third, when a vehicle passes the ETC lane, it slows down and passes slowly. There are two main reasons for the slowdown. First, ECT causes accidents when preventing vehicles from hitting railings. Second, ETC equipment requires vehicles to pass at low speeds.

\subsection{The shortcomings of non-deceleration ETC}

First, it is necessary to establish a high-precision system for evading fees and obtaining evidence, with large equipment investment and high tracking cost. Second, it is difficult to realize technically, especially how to prevent and curb evading vehicles is the key technology.

\section{Optimize design content of ETC}

The optimize design content of ETC is based on RFID technology. The function is to realize the non-deceleration ETC charge in the process of vehicle traffic. It mainly includes the following four aspects.

First, realize the non-deceleration ETC charges.

Second, put an end to escape fee.

Third, reduce construction costs.

Fourth, the application of key technologies is simple and feasible.

\section{The design ideas of Non-deceleration ETC based on RFID technology}

\subsection{Systemic}

The charge system is designed by the transportation department. Which will ensure that they are implemented as required.

\subsection{Universality}

The principle of universality is that the system is acceptable to the user. Why ETC charging system is not widely used in China, one of the important reasons is that ETC is independent and not unified. This charging system should be universal in the whole country. All vehicles in the country can pass and pay fees in the whole country, as long as they have license plates.

\subsection{Non-retarded passage}

Vehicles do not need to slow down when passing through toll booths or gantries. Which will keep traffic moving at high speed and avoid queues. This method greatly improves traffic efficiency.

\subsection{Reduce construction and management costs}

The current management mode of road and bridge charges in China costs a lot of construction cost, labor cost and management cost. Non-deceleration ETC can realize no one charge mode. At the same time, we can't build toll stations, only simple gantry. 


\section{System implementation method}

Non-deceleration ETC of vehicles is based on RFID technology, which combines charging stations, payment vehicles and Banks organically. Which forms a closed loop of information to realize non-deceleration electronic trigger automatic payment. The working process of the vehicle non-deceleration ETC system based on RFID technology is shown in the figure 1.

The system is consists of the following.

First, establish a unified national road and bridge toll electronic payment platform. The ministry of communications built a nationwide electronic toll collection platform. All toll authorities nationwide are centralized in the toll collection system management center. All road and bridge management enterprises shall apply to the ministry of communications for examination and approval. We can fundamentally solve the arbitrary charges and management loopholes. All charges will be collected by the center, and then transferred to the unit in time.

Second, establish a unified national RFID license plate recognition system. RFID identification commercial technology has been very mature, and the cost is very low. It has been widely used in the field of military vehicle management in China. So, it is feasible and economical for establishing a unified national RFID license plate recognition system.

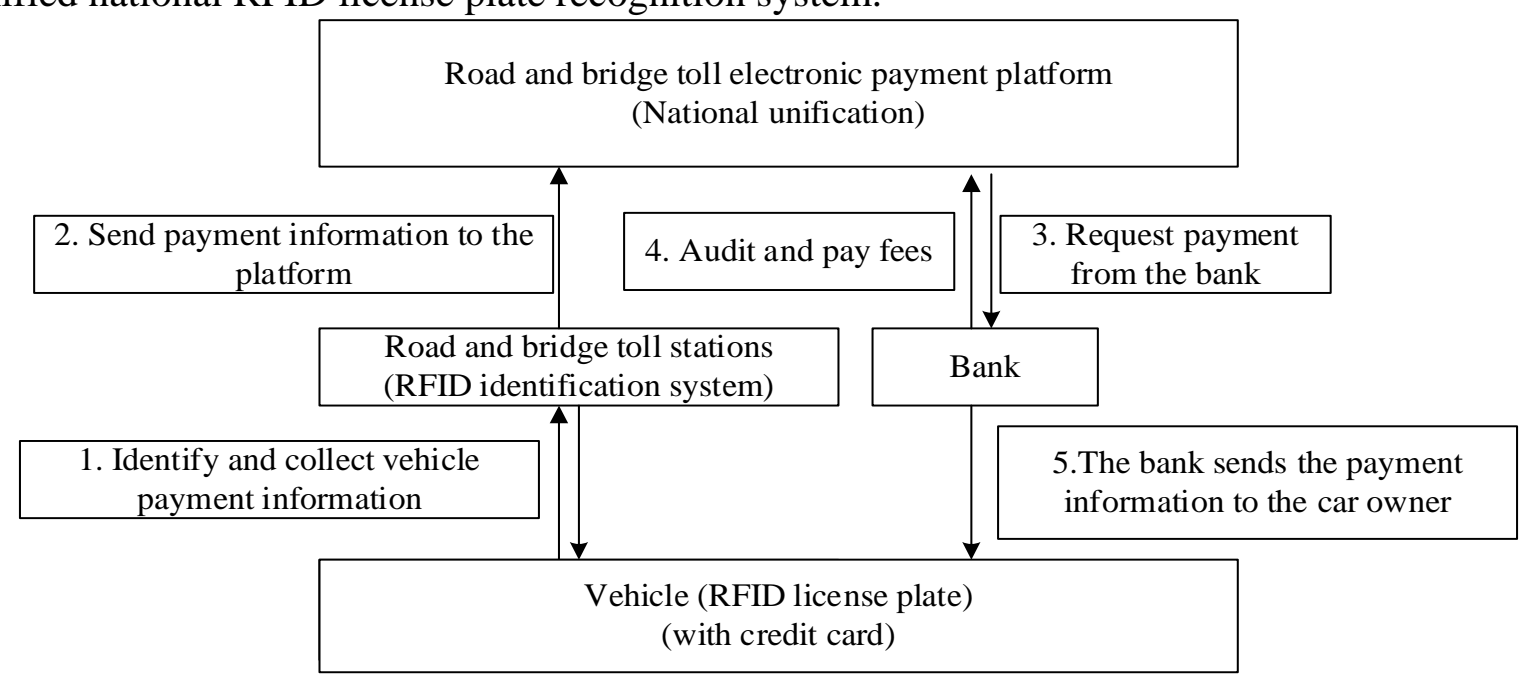

Figure 1 The working process of the vehicle non-deceleration ETC system based on RFID technology

Third, add national uniform RFID identification tags to the license plates. The traditional ETC system is an independent identification card or tag, which is not bound with the license plate. It only plays the payment function, but not the vehicle identification function. If the RFID tag is embedded in the license plate, it can realize the one-to-one correspondence between the license plate and the RFID tag, and each car has a unique RFID tag. Record the owner's relevant information in the RFID, such as name, gender, id number, credit card number, vehicle information, etc.

Fourth, fee payment system. In a traditional ETC system, there must be a fee in the ETC toll card used. Otherwise, it is impassable or fined. But in this fee payment system, the license plate is used to bind the owner's credit card information. Each plate is mandatory tied to the owner's bank credit card. This allows you to charge even if you don't have any money in the card, without worrying about the owner being impassable.

Fifth, Fees and fines are automatically deducted by credit card.

Six, inform the owner of credit card charges through bank SMS.

\section{Conclusions}

Compared with most current highway toll collection systems, the ETC system based on RFID technology has the following advantages.

First, it effectively improves the vehicle capacity, charging efficiency, and road and bridge utilization, reducing the cost of social passage. 
Second, it does not need to additional ECT charge CARDS, convenient for motorists.

Third, it can effectively avoid the situation of evading vehicle fees.

Fourth, it can reduce fuel consumption and protect the environment.

Fifth, it can accurately calculate the amount of road and bridge charges, put an end to corruption and enterprise financial opacity.

Sixth, it facilitates the formulation of charging policies. For example, during the period of free passage on holidays, China's high-speed kilometers are very congested, and the accident rate is rising. Road and bridge authorities can use RFID to develop a toll-free plan. During the year, every vehicle in the country can pass through all roads and Bridges in the country several times free of charge. This can effectively stagger the rush hour.

Seventh, it can provide the basis for the decision-making of the management organization. Road and bridge toll electronic payment platform can clearly understand the traffic flow of each road, bridge and tunnel during the period. These data can provide a reference basis, such as road and bridge management, fee standards, the construction of new road and bridge.

\section{References}

[1] Liu hui. Research on ETC charging system based on RFID [J]. Private science and technology. 2014(10).

[2] Sun qinkai. Design and implementation of expressway toll collection system in intelligent transportation system [J]. Friends of science. 2012(07). 